\title{
Life-threatening Traumatic Rupture of an Intrahepatic Portal Vein
}

\author{
Chan Yong Park', Seok Ran Yeom², Hyun Min Cho ${ }^{1}$ \\ ${ }^{1}$ Department of Trauma Surgery, Pusan National University Hospital, Busan, Korea \\ ${ }^{2}$ Department of Emergency Medicine, Pusan National University Hospital, Busan, Korea
}

Reports of life-threatening hemorrhage due to portal vein rupture are extremely rare. We report a case of massive bleeding due to intrahepatic portal vein rupture. A 17-year-old man presented to the emergency department (ED) via another hospital after a motorcycle accident. Cardiopulmonary resuscitation (CPR) was performed 20 minutes before arrival to the ED. CPR was continued after arrival but the patient died without return of spontaneous circulation (ROSC). Abdominal computed tomography (CT) performed at a previous hospital showed massive extravasation of contrast from the intrahepatic portal vein.

(Trauma Image Proced 2017(1):13-14)

Key Words: Portal Vein; Injuries; Hemorrhage; Liver

\section{CASE}

A 17-year-old man presented to the emergency department (ED) via another hospital after a motorcycle accident. Cardiopulmonary resuscitation (CPR) was performed 20 minutes before arrival to the ED. CPR was continued after arrival but the patient died without return of spontaneous circulation (ROSC). Laboratory

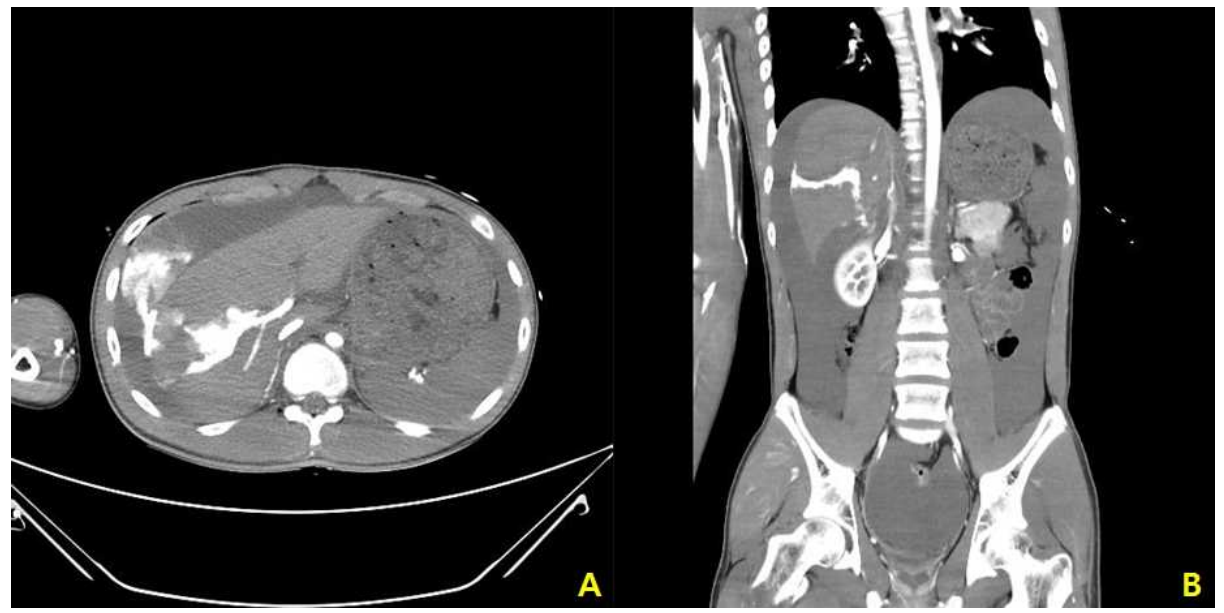

Fig. Abdominal CT demonstrates massive extravasation of contrast from the intrahepatic right portal vein on axial (A) and coronal (B) views. Liver and spleen are not enhanced.

Received: March 4, 2017 Revised: April 5, 2017 Accepted: April 12, 2017

Correspondence to: Chan Yong Park, Department of Trauma Surgery, Pusan National University Hospital, 179, Gudeok-ro, Seo-gu, Busan, Korea

Tel: 82-51-240-7369, Fax: 82-51-240-7719, E-mail: wkafyddl@hanmail.net

Copyright (c) 2017 Korean Association for Research, Procedures and Education on Trauma. All rights reserved.

(c) This is an open-access article distributed under the terms of the Creative Commons Attribution Non-Commercial License (http://creativecommons.org/ licenses/by-nc/4.0) which permits unrestricted noncommercial use, distribution, and reproduction in any medium, provided the original work is properly cited 
examination revealed a white blood count (WBC) $3.51 \times$ $10^{3} / \mu \mathrm{L}$, hemoglobin $(\mathrm{Hb}) 1.6 \mathrm{~g} / \mathrm{dL}$, platelet $16 \times 10^{3}$ $/ \mu \mathrm{L}$, lactic acid $15.0 \mathrm{mmol} / \mathrm{L}$, and base excess -25.8 . Abdominal computed tomography (CT) performed at a previous hospital showed massive extravasation of contrast from the intrahepatic right portal vein (Fig.).

\section{DISCUSSION}

Traumatic injuries to the portal vein are rarely reported. Reports of life-threatening hemorrhage due to intrahepatic portal vein rupture are extremely rare. Severe bleeding from the portal vein is treated surgically, such as via packing or ligation. Henne-Bruns et al. (1) reported 5 cases of portal vein injury, including two treated with reconstruction of the portal vein and prothetic graft implantation, one with reanastomosis of the portal vein, and two with oversewing of the portal vein. Sundarakumar et al. (2) reported endovascular intervention for traumatic portal venous hemorrhage complicated by portal hypertension.

\section{Conflict of Interest Statement}

This work was supported by clinical research grant from Pusan National University Hospital in 2017.

\section{REFERENCES}

1. Henne-Bruns D, Kremer B, Lloyd D, Meyer-Pannwitt U. Injuries of the portal vein in patients with blunt abdominal trauma. HPB Surgery. 1993;6(3):163-8.

2. Sundarakumar DK, Smith CM, Lopera JE, Kogut M, Suri R. Endovascular interventions for traumatic portal venous hemorrhage complicated by portal hypertension. World journal of radiology. 2013;5(10):381. 